\title{
Experimental enhancement of corticosterone levels positively affects subsequent male survival
}

\author{
J. Cote ${ }^{a, *}$ J. Clobert ${ }^{a}$, S. Meylan ${ }^{\text {a }}$, P.S. Fitze ${ }^{a, b}$ \\ ${ }^{a}$ Laboratoire Fonctionnement et Evolution des Systèmes Ecologiques, Université Pierre et Marie Curie, 7, quai Saint-Bernard, \\ Bâtiment A, $7^{\text {ème }}$ étage, case 237, 75005 Paris, France \\ ${ }^{\mathrm{b}}$ Department of Zoology, University of Cambridge, Downing Street, Cambridge CB2 3EJ, UK
}

Received 9 May 2005; revised 9 August 2005; accepted 9 August 2005

Available online 8 September 2005

\begin{abstract}
Corticosterone is an important hormone of the stress response that regulates physiological processes and modifies animal behavior. While it positively acts on locomotor activity, it may negatively affect reproduction and social activity. This suggests that corticosterone may promote behaviors that increase survival at the cost of reproduction. In this study, we experimentally investigate the link between corticosterone levels and survival in adult common lizards (Lacerta vivipara) by comparing corticosterone-treated with placebo-treated lizards. We experimentally show that corticosterone enhances energy expenditure, daily activity, food intake, and it modifies the behavioral time budget. Enhanced appetite of corticosterone-treated individuals compensated for increased energy expenditure and corticosteronetreated males showed increased survival. This suggests that corticosterone may promote behaviors that reduce stress and it shows that corticosterone per se does not reduce but directly or indirectly increases longer-term survival. This suggests that the production of corticosterone as a response to a stressor may be an adaptive mechanism that even controls survival.
\end{abstract}

(C) 2005 Elsevier Inc. All rights reserved.

Keywords: Corticosterone; Stress; Survival; Behavior; Common lizard; Lacerta vivipara; Activity; Food consumption

\section{Introduction}

In response to stressful conditions, animals modify their behavior and physiology to avoid or balance negative effects of stress (Wingfield and Ramenofsky, 1999). A widespread physiological response is the production of glucocorticoids by the adrenal cortex (Harvey et al., 1984). This production leads to modifications in different physiological and behavioral processes (Greenberg and Wingfield, 1987; Lance, 1990; Silverin, 1998; Wingfield and Ramenofsky, 1999; Moore and Jessop, 2003) usually associated to enhanced energy consumption. Specifically, there is an increase of the energetic expenditure associated to greater catabolic processes (Holmes and Phillips, 1976). Beside many studies investigating the physiological and behavioral

\footnotetext{
* Corresponding author. Fax: +33 144273516 .

E-mail address: jcote@snv.jussieu.fr (J. Cote).
}

consequences of corticosterone in laboratory conditions (Sapolsky et al., 2000), some studies were conducted under field conditions in birds and reptiles (e.g., Astheimer et al., 1992; Breuner et al., 1998; Belliure et al., 2004; Moore and Mason, 2001, reviewed in Wingfield and Ramenofsky, 1999). Corticosterone, which is a widespread glucocorticoid in vertebrates, is shown to decrease reproductive and social activity and is suggested to increase locomotor activity in several vertebrates (Greenberg and Wingfield, 1987; DeNardo and Licht, 1993; Breuner et al., 1998, see also Astheimer et al., 1992; Moore and Jessop, 2003). Enhanced locomotor activity usually leads to better foraging capacity and to increased dispersal (Huey et al., 1984; Bennett and Huey, 1990; de Fraipont et al., 2000; Clobert et al., 2000), suggesting that corticosterone modifies behavior in order to directly or indirectly enhance survival (Wingfield and Ramenofsky, 1999; Breuner and Hahn, 2003). Increased dispersal may be an optimal strategy to escape stressful small-scale events that persist over a long time. To disperse 
would however be less adaptive if the stressful event only lasts for a short period or if conditions are not better, or even worse, in the potential dispersal area. It is therefore not surprising that long-lasting stressors (e.g., high animal density, or deviating climatic variables) have been suggested to provoke different physiological and behavioral responses than acute stressors (Silverin, 1998).

It is known that long-lasting stressors often lead to constantly enhanced corticosterone levels (Pravosudov et al., 2001; Romero and Wikelski, 2001), and that they may have negative consequences affecting immunocompetence, neural degeneration, or mortality (Morici et al., 1997; Berger et al., 2004, reviewed in McEwen et al., 1997 and in Sapolsky et al., 2000). Furthermore, long-lasting stress is frequently associated with increased energy expenditure (Pravosudov et al., 2001; Romero and Wikelski, 2001) and thus should be compensated for (Tataranni et al., 1996; Kitaysky et al., 2003). Some studies showed that enhanced stress might be compensated for by increased food consumption (reviewed in Sapolsky et al., 2000). For example, Lin et al. (2004) showed that corticosteronetreated broiler chickens increased their energy expenditure and consumed more food relative to their body weight. This suggests that corticosterone mediates the compensatory behavior and thus that releasing corticosterone into the blood may be an adaptive response to stressors.

In contrast to this hypothesis, several clinical studies and some observational field studies showed that stressors increase the blood corticosterone levels as well as mortality (McEwen et al., 1997; Morici et al., 1997; Romero and Wikelski, 2001; Eriksen et al., 2003). While many laboratory studies mainly investigate the physiological costs and thus exclude interactions with behavior, ecology, and the social environment, they usually do not disentangle the effects of the stressor and the effects of the corticosterone per se. For this reason, it is possible that the increased mortality in the stressed group would have been even higher without the presence of the increased blood corticosterone levels and thus that corticosterone may have positive effects on survival. Evidence that producing corticosterone might be an adaptive strategy to enhance survival and individual fitness comes from two field studies where corticosterone was exogenously administered on lizards (Sinervo and DeNardo, 1996; Comendant et al., 2003). These studies disentangled the effects of stressors and the effects induced by corticosterone in female lizards and found that the survival of the corticosterone administered females was enhanced in one, but not all years. Since the positive effect was found in one single year and since several other studies suggest that corticosterone may have negative but not positive effects, the effects of corticosterone are still far from understood (e.g., McEwen et al., 1997; Sapolsky et al., 2000). Consequently, evidence that corticosterone may be an adaptive mechanism that enhances survival is needed.

Here, we experimentally test the effect of long-lasting enhanced blood corticosterone levels on activity, body mass change, food consumption, and survival of adult male and female lizards, independent of the stressors. According to the current experimental evidence, we predict greater energy expenditure, enhanced food consumption, and enhanced activity for lizards treated with corticosterone.

\section{Methods}

Species, study site, and breeding conditions

The common lizard (Lacerta vivipara Jacquin, 1787) is a small lacertidae (adult snout-vent length: males $40-60 \mathrm{~mm}$, females $45-75 \mathrm{~mm}$ ) inhabiting humid habitats in Eurasia. It eats small insects, spiders, and earthworms (Avery, 1962) and its behavior is cryptic and difficult to observe under natural conditions (Clobert et al., 1994). Lizards become active in late March-beginning of April (Massot et al., 1992) and hibernation starts in late September. The winter survival of lizards in good body condition is usually higher than that of those in poorer body condition (Sorci and Clobert, 1999).

Prior to the experiment, in June 2002, we collected 176 adult $(>1$ years old) common lizards ( 88 males and 88 pregnant females) from 4 different populations in Southern France (all of them were located in the vicinity of the Mont Lozère, France, $44^{\circ} 27^{\prime} \mathrm{N}, 3^{\circ} 44^{\prime} \mathrm{E}$ ). The collection of both sexes allowed for the determination of sex-differences in the stress response. For later identification, lizards were individually marked by toe-clipping. To provide each lizard with the same standardized environment (food, water, heat, social interactions), lizards were individually housed in plastic terrariums $(25 \times 15.5 \times 15 \mathrm{~cm}$, Le Galliard et al., 2003) containing a litter of $3 \mathrm{~cm}$ at the Ecological Research Station of Foljuif (Seine-et-Marne, $48^{\circ} 17^{\prime} \mathrm{N}, 2^{\circ} 41^{\prime} \mathrm{E}$ ). In one corner of the terrarium a bulb provided heat for thermoregulation and light from 9:00 a.m. to 12:00 a.m. and from 1:00 p.m. to 5:00 p.m.. An egg carton and a plastic tube were added allowing the lizards to hide. Lizards were able to behave normally and escaping behavior (e.g., scratching on the walls) was rare $(1,3 \%$ of the time during behavioral test). The authors attest the adherence to the National Institutes of Health Guide for Care and Use of Laboratory Animals. Female lizards gave birth in the terrarium and all offspring were thereafter released into semi-natural populations. After the last female gave birth (approximately 1 month after capture), all lizards were kept for another 2 weeks under the same standardized conditions. Thereafter the described experiment was started (July 2002).

\section{Experimental corticosterone application}

44 females and 44 males (11 lizards of each population and of each sex) were randomly chosen and treated with corticosterone, while the remaining 44 females and 44 males were placebo treated. Because temperature is very important 
for reptiles (Huey, 1974) and since it might be heterogeneous in the rearing room, we randomly distributed the same number of treatments and sexes per shelf and floor. There was no effect of the position (shelf and floor) on treatment, sex, body size, and body mass $(P>0.45$ for shelf, floor, and all interactions). There were no morphological differences between the treatment groups (snout-vent length: $F_{1,173}=$ $0.04, P=0.83$ and body mass: $F_{1,173}=0.01, P=0.91$ ).

The corticosterone treatment consisted of a daily application of $4.5 \mu$ of sesame oil mixed with corticosterone ( $3 \mu \mathrm{g}$ of corticosterone per $\mu \mathrm{l}$ of oil), while the placebo treatment consisted of a daily application of $4.5 \mu \mathrm{l}$ of sesame oil only. The application was realized in the evening on the back of the lizards daily for 22 days (for more details see Meylan et al., 2003) starting on the second day of the experiment. Hormonal treatments were applied in the evening for two reasons. First, the temperature in the terrariums decreased during the evening so the lizards were less active and more easily handled. Second, lower temperature reduced the risk of evaporation of the solution before it crossed the skin. This non-invasive method is similar to that described by Knapp and Moore (1997). It has been frequently used in the common lizard and has been shown to enhance basal corticosterone levels (Meylan et al., 2003; Belliure et al., 2004). Meylan et al. (2003) found that basal blood corticosterone levels of free-living females that were housed in the laboratory for 1 day averaged $21.64 \mathrm{ng} / \mathrm{ml}$ (max. $101.97 \mathrm{ng} / \mathrm{ml}$ ). In June 2002, we additionally captured another 49 females and 21 males in two natural populations located in the vicinity of the Mont Lozère (France, $44^{\circ} 27^{\prime} \mathrm{N}, 3^{\circ} 44^{\prime} \mathrm{E}$ ) to investigate sex differences in basal blood corticosterone levels. To allow the lizards to recover from capture-induced stress, they were as well housed in the laboratory for 1 day before blood sampling. The blood corticosterone levels were analyzed using the same method as described in Meylan et al. (2003). The basal corticosterone levels averaged: $77.03 \pm 5.44 \mathrm{ng} / \mathrm{ml}$ (range: 1 to $181 \mathrm{ng} / \mathrm{ml}$ ), and there were no significant differences between the sexes $\left(F_{1,66}=1.58, P=0.21\right)$. In Meylan et al.'s study, the same transdermal corticosterone application that was used in this experiment was applied daily for 20 days. It led to an increase of the blood corticosterone levels within $1 \mathrm{~h}$. Thereafter, the blood corticosterone levels remained at a similar level over the subsequent 2 days, and rose to an average of $281.9 \mathrm{ng} / \mathrm{ml}$ that remained almost constant over the remaining 15 study days (Meylan et al., 2003). Thus, transdermal corticosterone application led to a five- to ten-fold increase of the basal blood corticosterone levels and to an average level being $100 \mathrm{ng} / \mathrm{ml}$ above the blood concentration measured in natural populations. Our manipulation does probably not yet correspond to pharmacological doses but to high physiological doses because it was most likely still within the naturally occurring range of acute stress that can rise blood corticosterone levels of reptiles more than ten times the basal levels (e.g., Tyrrell and Cree, 1998). During the indoor experiments and after release into the semi-natural populations, we omitted measuring the blood corticosterone levels because taking blood would most likely have affected the survival of the lizards (Meylan et al., 2003) and because data on the effects of administering corticosterone during a similar time period (June-July) and for a similar number of days (20 days) already exists (Meylan et al., 2003).

\section{Body mass measurement and food consumption}

Each lizard was offered 1 Pyralis sp. larva every 5 days starting on the second day of the experiment. Only larvae of similar body mass were used for feeding $(254 \mathrm{mg} \pm 12.64$ $\mathrm{SE})$. No food was present in the terrariums and terrariums were closed with grids of narrow width of mesh. Consequently, lizards were able to eat food provided by us only. Alive larvae were presented to the lizards with pliers between 11:30 and 12:30. Lizards either immediately accepted (attacked and ate the larvae) or refused the food item. In the latter case, we left the larva in the terrarium and we checked in the evening if the larva had been eaten. This procedure avoided confounding the appetite with a refusal due to human induced stress. The body mass of each lizard was measured with a precision of $2 \mathrm{mg}$ both on the first day of the experiment (the day before the first feeding) and on the 24th day of the experiment (two days after the last feeding). Water was available ad libitum.

\section{Activity}

Activity was measured in the rearing terrarium on the 19th day of the experiment. As lizards spent the night below the egg carton, in the ground, or in the tube, they were hidden to the observer. Each 15 min starting on 9:00 a.m. until 12:00 a.m., a naive observer noted if lizards were active and thus visible (out of the egg carton, out of the ground, or out of the tube). If they were visible, the observer distinguished between four behaviors: basking below the light (upright head position and increased respiration, see Carpenter and Ferguson, 1977; Huey, 1982 for a precise description), moving (walking around in the terrarium), scratching (de Fraipont et al., 2000), or being immobile (see Lecomte (1993) for a completed review of behaviors). An inactive lizard (not moving, scratching or basking) was defined as being immobile. A lizard grating on the walls of the terrarium or in the soil was defined as scratching (de Fraipont et al., 2000). After emergence, we counted the number of times a lizard showed a given behavior (basking, scratching, moving, being immobile). The time of emergence is considered as the time when a lizard left his overnight shelter for the first time.

\section{Survival}

At the end of August 2002 (two days after the last corticosterone application), lizards were released into 5 
outdoor enclosures. Enclosures contain of $10 \times 10 \mathrm{~m}$ of natural habitat being enclosed by plastic walls and being protected from terrestrial and avian predators (Lecomte and Clobert, 1996). All lizards were recaptured by hand in April 2003 over 8 successive days. Body mass and snout-vent length was measured. Captured lizards were brought to the laboratory where they were housed until the capture was finished. All lizards were recaptured within the first two capture days. The escape-proof enclosure and the absence of alive lizards during the subsequent six capture days guaranteed that all survivors were collected. Because the common lizard is living in dense vegetation and because it intensively uses natural cavities and mouse holes, it was not possible to find dead lizards, which made an identification of the cause of mortality impossible. For these reasons and due to the cryptic behavior of this species it is as well difficult to observe the lizard's behavior in the outdoor enclosures and thus behavioral measurements following release were omitted.

For the survival measurement, lizards of different sexes were released in enclosures containing one sex only (3 enclosures for males and 2 enclosures for females). These enclosures also contained non-experimental lizards of the same sex as the released lizards. Non-experimental lizards were non-treated lizards, which were held in the laboratory for a similar length of time as the lizards used in this experiment. After releasing the experimental lizards, all enclosures contained the same total number of individuals. Per enclosure, we released the same number of individuals of each treatment (male enclosures: 12, 14, or 18 of each treatment; female enclosures: 22 of each treatment in one enclosure and in the other enclosure 22 and 21 females (one female died during the experiment)). Body mass and body size did not differ between enclosures $(P>0.25$, for simple effects and all interactions).

\section{Statistics}

The number of larvae eaten and the activity parameters (time of emergence, numbers of each behavior) were analyzed by using the GENMOD procedure in SAS v8.02 with a logistic regression, a cumulative logit link, and a multinomial distribution. We conducted a repeated measures logistic regression with the counts of each behavior (basking, scratching, moving, being immobile) as four repeated measures per individual (GEE model). This analysis allows for the estimation of treatment-induced differences in the partitioning of the time budget among the four behaviors. The body mass change during the experiment (body mass after the end of the treatment minus body mass before the beginning of the treatment) was analyzed using Proc GLM. Heteroscedasticity and normality assumptions of the residuals were in all presented models fulfilled. Survival was determined as $0=$ not survived and $1=$ survived and it was analyzed using the GLIMMIX procedure (Littell et al., 1996) using a logit link function and a binomial error term. The full model contained the simple factors (treatment, sex, enclosure) and all interactions. Enclosures were modeled as a random effect nested within sex. Simplification of all models was made using backward elimination of the non-significant interactions and factors. For the analysis of the body condition, body mass was the dependent variable and the body length was added to the model as covariate (Darlington and Smulders, 2001). The significance level was set at $P=0.05$. As population of origin and its interactions with the treatment were not significant in any analyses $(P>0.20)$, we do not present these effects. One female treated with placebo died before release and was therefore excluded from the analyses.

\section{Results}

\section{Food consumption and body mass}

Lizards treated with corticosterone ate more larvae during the experiment than lizards treated with placebo $\left(\chi_{1}^{2}=15.35, P<0.001\right.$, Fig. 1A). Females ate more than males $\left(\chi_{1}^{2}=27.50, P<0.001\right)$ and there was no significant interaction between treatment and $\operatorname{sex}\left(\chi_{1}^{2}=0.53, P=\right.$ $0.467)$, showing that the corticosterone application induced the same appetite enhancement in males and females. Separate analyses show that in the corticosterone-treated individuals the appetite was increased in both males $\left(\chi_{1}^{2}=\right.$ 9.40, $P=0.0022)$ and females $\left(\chi_{1}^{2}=4.97, P=0.0258\right)$.

Corticosterone had no significant effect on the body mass change when using a model that did not include food consumption $\left(F_{1,172}=0.002, P=0.96\right)$. Since the corticosterone effect on appetite could hide an effect of the hormone treatment on the body mass change, we included the food consumption into the model as a covariate. Food consumption was positively correlated with the body mass change (Table 1) and corticosterone-treated individuals increased their body mass less than placebo-treated individuals (Table 1, Fig. 1B). Females put on significantly more body mass than males (Table 1, Fig. 1B). And there was no significant interaction between the sex and the corticosterone treatment in body mass change (Table 1). Separate analyses show that body mass change was more positive in corticosterone-treated males $\left(F_{1,85}=4.07, P=\right.$ $0.047)$ and females $\left(F_{1,84}=7.58, P=0.0072\right)$ compared to placebo-treated animals.

\section{Activity}

Lizards treated with corticosterone were active significantly earlier in the morning (Table 2A, Fig. 2) than placebo-treated lizards. There were no significant differences between males and females (Table 2A), and the interaction between treatment and sex was not significant $\left(\chi_{1}^{2}=0.11, P=0.227\right)$. We analyzed the partitioning of the time among the four quantified behaviors using a repeated 
(a)

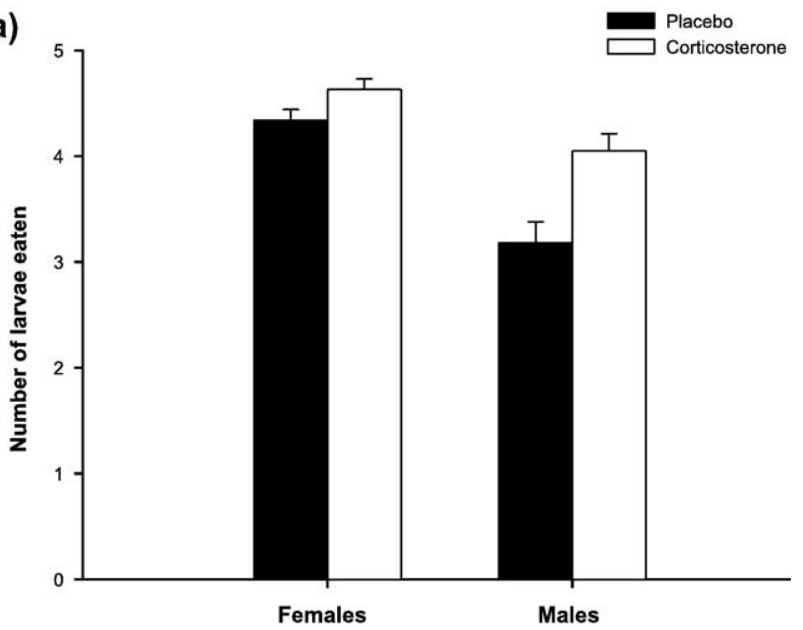

(b)

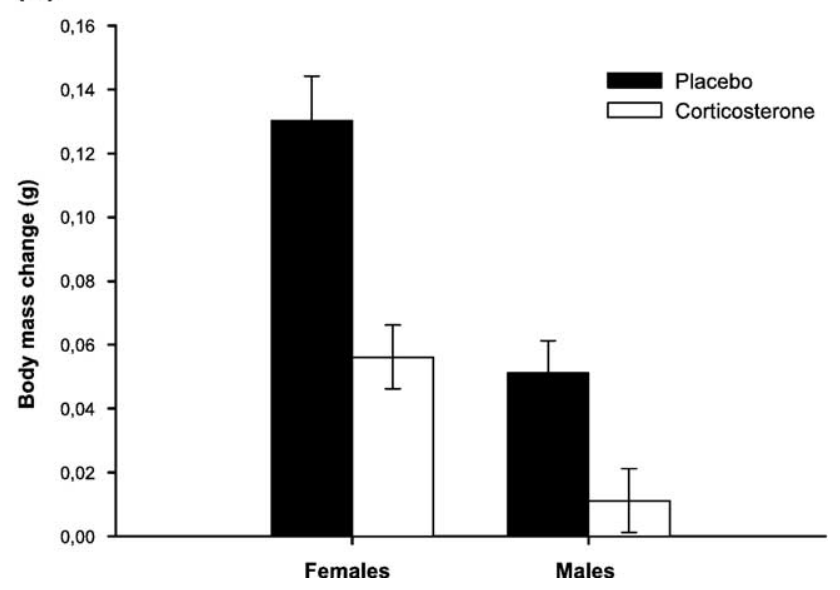

Fig. 1. (a) Food consumption in relation to the corticosterone treatment in female and male lizards. Shown are the mean numbers of larvae eaten $( \pm$ S.E.) during the 22 days of treatment. (b) Treatment induced mean $( \pm$ S.E. $)$ body mass change (body mass at the end of the laboratory experiment-body mass at the start of the experiment) of male and female lizards adjusted for food consumption.

measurements model. As lizards treated with corticosterone were active earlier, we were able to quantify their behavior during a longer period. Emergence and activity patterns could thus be confounded. We therefore included the time a lizard was active (the number of times the lizard's behavior was quantified between emergence and 12 o'clock), hereafter referred to as 'activity length', as a covariate in the repeated measures analysis. Activity length and the type of behavior explained a significant part of the variance (Table

Table 1

Body mass change in relation to corticosterone treatment, sex and food consumption

\begin{tabular}{lcccc}
\hline Factors & $d f$ & $\mathrm{~F}$ & $\mathrm{P}$ & $\begin{array}{l}\text { \% variance } \\
\text { explained }\end{array}$ \\
\hline Treatment & 1,171 & 7.108 & 0.008 & 2 \\
Sex & 1,171 & 11.291 & 0.001 & 3 \\
Interaction & 1,170 & 1.47 & 0.227 & 0.004 \\
Number of larvae eaten & 1,171 & 98.029 & $<0.001$ & 29 \\
\hline
\end{tabular}

Table 2

Activity in relation to corticosterone treatment and sex

\begin{tabular}{lll}
\hline & (A) Emergence & (B) Quantity of behavior \\
\hline Corticosterone & $\chi_{1}^{2}=12.23, P=0.001$ & $\chi_{1}^{2}=0.00, P=0.987$ \\
Sex & $\chi_{1}^{2}=0.06, P=0.805$ & $\chi_{1}^{2}=0.09, P=0.759$ \\
Type of behavior & & $\chi_{3}^{2}=142.14, P<0.001$ \\
Corticosterone $\times$ Type & & $\chi_{3}^{2}=8.50, P=0.037$ \\
Activity length & & $\chi_{1}^{2}=36.25, P<0.001$ \\
\hline
\end{tabular}

(A) Effect of corticosterone treatment and sex on the time of emergence from the overnight stay. Logistic regression with a multinomial distribution and a cumulative logit link. (B) Effect of corticosterone treatment, sex, and activity length on the number of times a given behavior was observed. Repeated measures logistic regression (multinomial distribution and cumulative logit link) with the type of behavior (immobility, basking, moving, scratching) as repeats.

2B). The interaction between corticosterone treatment and the type of behavior was significant (Table 2B, Fig. 3), showing that lizards treated with corticosterone partitioned their time of activity differently among behaviors. The corticosterone treatment per se and the sex did not significantly affect the behavior (Table 2B). The interactions of the corticosterone treatment and the type of behavior with sex were not significant $\left(\operatorname{sex} \times\right.$ corticosterone: $\chi_{1}^{2}=2.09$, $P=0.148$; sex $\times$ type: $\left.\chi_{1}^{2}=2.78, P=0.596\right)$. To investigate the significance of the corticosterone treatment on the partitioning of the time among behaviors (interaction: corticosterone $\times$ type of behavior) we applied independent contrasts. Lizards treated with corticosterone were significantly less immobile and basked more than placebo-treated lizards (immobility: $\chi_{1}^{2}=4.28, P=0.039$; basking: $\chi_{1}^{2}=$ $5.42, P=0.020$, Fig. 3). There was no significant effect of the treatment on scratching and moving (scratching: $\chi_{1}^{2}=$ 1.63, $P=0.202$; moving: $\chi_{1}^{2}=2.02, P=0.155$, Fig. 3 ).

\section{Survival}

32 of 44 corticosterone and 19 of 44 placebo-treated males survived until spring 2003, while 9 of 44 cortico-

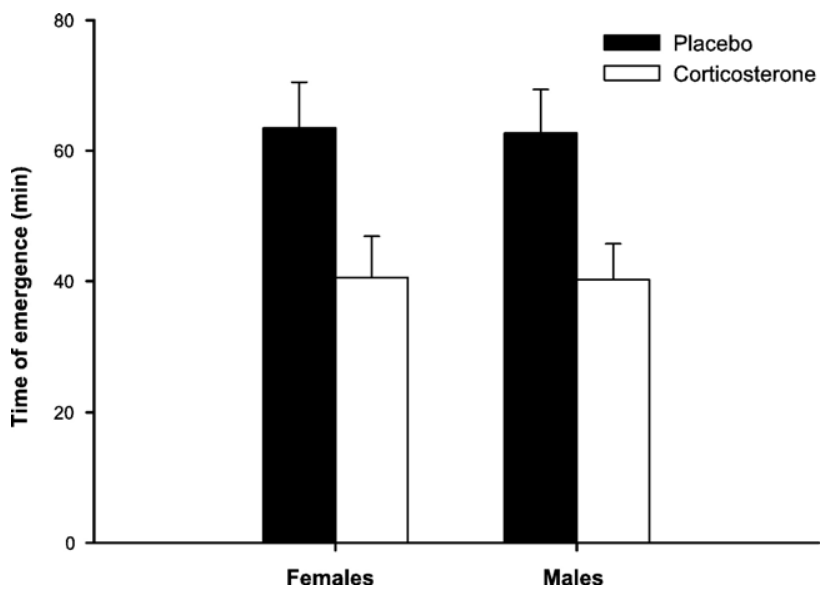

Fig. 2. Time of emergence from the overnight stay of female and male lizards in relation to the corticosterone treatment. Mean time of emergence (min after 9:00 a.m. \pm S.E.) per sex and treatment group shown. 


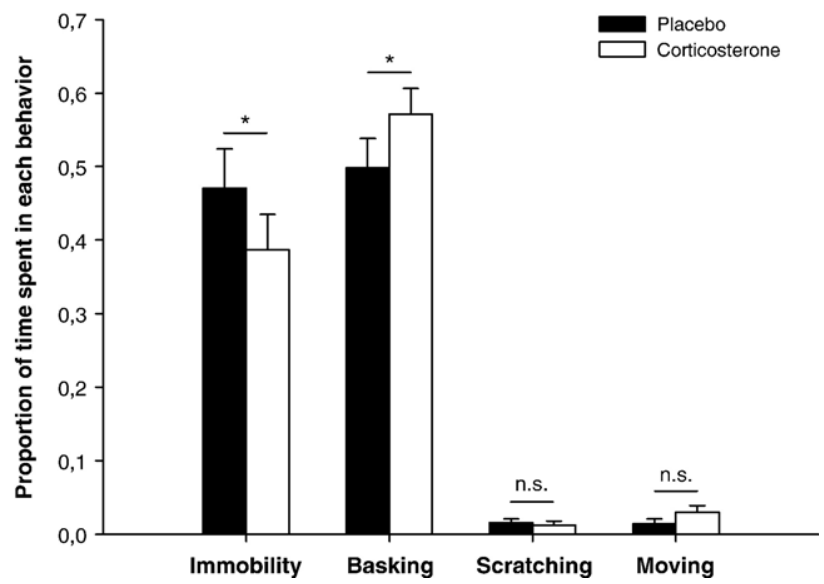

Fig. 3. Partitioning of the time between the different behaviors in relation to the corticosterone treatment. The graph shows the proportion of time a lizard spent immobile, basking, moving or scratching between emergence from the overnight stay until 12 a.m. An asterisk (*) represents a significant difference between treatments.

sterone and 13 of 43 placebo-treated females survived. Males had a higher survival probability than females $\left(F_{1,3}=\right.$ 15.65, $P=0.029$, males $=0.58 \pm 0.05$ females $=0.25 \pm$ $0.05)$ and there was a significant interaction between the sex and the corticosterone treatment on survival $\left(F_{1,168}=6.78\right.$, $P=0.010$, Fig. 4). Corticosterone-treated males $\left(F_{1,84}=\right.$ $7.60, P=0.007)$, but not females $\left(F_{1,84}=1.06, P=0.305\right)$, showed significantly enhanced survival and there was no main effect of corticosterone treatment on survival $\left(F_{1,168}=\right.$ 1.15, $P=0.284$ ). Placebo-treated lizards survived with the similar probability as the non-experimental lizards (Survival probability per enclosure averaged over all enclosures: placebo lizards: $36 \% \pm 0.12$ se, non-treated lizards: $30 \% \pm$ 0.15 se, $F_{1,109}=1.43 P=0.235$ ). The corticosterone treatment did not have long-lasting effects on body condition $\left(F_{1,66}=1.41, P=0.239\right)$, on body size $\left(F_{1,67}=\right.$ $0.12, P=0.733)$, or on growth $\left(F_{1,67}=0.22, P=0.642\right)$.

\section{Discussion}

This experiment shows that corticosterone enhances food consumption, modifies behavior, and directly or indirectly affects male survival.

Lizards spent most of their time basking and immobile. Contrasting to another study in this species corticosterone did not significantly enhance the frequency of moving behavior (e.g., Belliure et al., 2004). However, corticosterone-treated lizards became active earlier in the morning and spent less time immobile after emergence, suggesting that their daily activity was increased. This supports the hypothesis that corticosterone enhances activity, potentially leading to the avoidance or compensation of the negative effects of the stressor (Wingfield and Ramenofsky, 1999; Breuner et al., 1998; de Fraipont et al., 2000; Breuner and Hahn, 2003). In some contexts enhanced activity could however be negative for the lizard due to greater foraging or dispersal movements and the resulting increased predation risk (Christian and Tracy, 1981; Clobert et al., 2000).

Lizards treated with corticosterone did not get heavier than placebo-treated lizards, but corticosterone significantly enhanced food consumption, showing that they put on less weight per food item. Consistent with other studies, this result suggests that corticosterone-treated lizards expended more energy due to corticosterone induced higher metabolic and behavioral activity (Gleeson et al., 1993; Tataranni et al., 1996; Breuner and Hahn, 2003). Despite the enhanced activity, lizards did not reduce body mass, showing that they compensated enhanced energy expenditure by increasing food consumption (e.g., Tataranni et al., 1996; Kitaysky et al., 2003).

In this study, survival, which can be a major component of fitness, was affected by the corticosterone treatment. Males treated with corticosterone survived significantly better than those treated with placebo and there was no effect in females. Several non-mutually exclusive hypotheses may explain how survival could have been affected by the corticosterone treatment. First, body condition, which is an important factor determining survival (Sorci and Clobert, 1999), may have been enhanced due to the increased food consumption. Because there were no condition differences between the treatment groups neither before nor after hibernation, this hypothesis is unlikely. Second, corticosterone might have reduced the social interactions (Tokarz, 1987; DeNardo and Licht, 1993) and thus the intrasexual competition in the outdoor enclosures, which may have led to increased survival. Because females are less aggressive than males (Heulin, 1988) and because lizards were maintained in enclosures consisting of one sex, female survival may not have been affected by the corticosterone treatment. However, in male-enclosures the male-male competition might have been high and certainly higher than in a mixed-sex enclosure of the same population density. Thus, corticosterone which reduces the social interactions

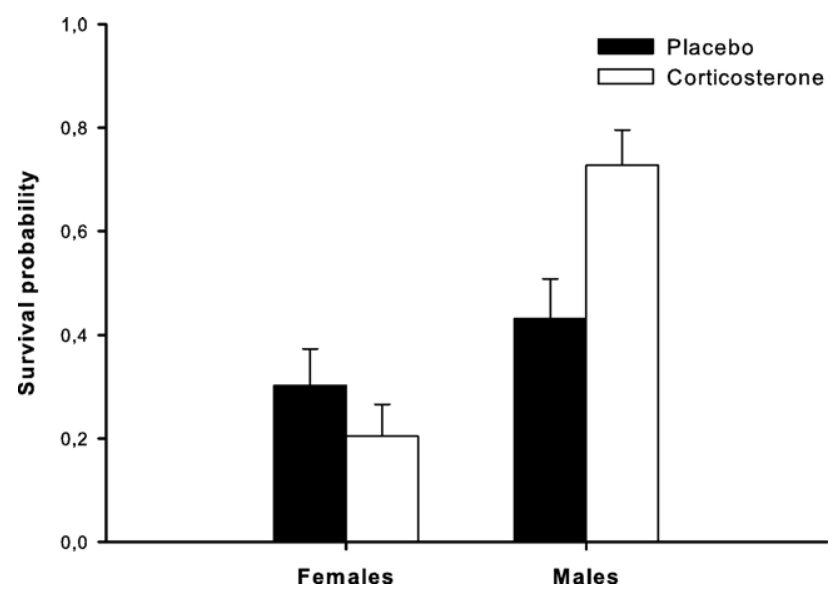

Fig. 4. Survival of placebo- and corticosterone-treated male and female lizards from September to April. Mean survival probability ( \pm S.E.) between treatments and sexes is shown. 
(Tokarz, 1987; DeNardo and Licht, 1993) may have led to a better survival of the corticosterone treated compared to the placebo-treated individuals. Besides these mechanisms, there are many other possible mechanisms that may have led to the increased survival of corticosterone-treated males. In this study, we, however, cannot distinguish between direct corticosterone effects or corticosterone-induced behavioral and physiological changes that led to increased survival, because reliable behavioral data after release are hard to obtain, because blood corticosterone levels before and after hibernation are unknown, and most importantly because the underlying mechanisms can only be explored using specifically designed experiments.

The absence of a corticosterone effect on females' survival could be due to several mechanisms including: sex-differences in hormonal levels (DeNardo and Sinervo, 1994a,b; Knobil and Neill, 1994; Jones et al., 1997), immunoglobulin levels (Tschirren et al., 2003), behavioral patterns (Heulin, 1988), life-history traits (Pilorge et al., 1987), and ecological requirements (Pilorge et al., 1987). Trying to understand the mechanisms is far beyond the scope of the present experiment. Consequently, further experiments are needed to explain the mechanisms leading to the observed sex-differences in survival.

Contrary to our study, Romero and Wikelski (2001) found a negative correlation between survival and the corticosterone level in wild iguanas. In Romero and Wikelski's study, El Niño led to both decreased food availability and increased corticosterone levels. Therefore, the negative correlation between corticosterone and survival in this particular study might be explained by reduced food availability. Our study, clearly shows, that corticosterone has direct or indirect (via its effects on behavior and physiology) positive effects on male survival and no negative effects on female survival. These findings are further supported by similar results showing that juvenile common lizards born from corticosterone-treated mothers as well survived better (Meylan and Clobert, 2005). It further suggests that animals suffering from external stressors may compensate the effects of the stressors on body condition by enhancing, e.g., food intake. As a result, corticosterone levels might be increased, but they may not necessarily lead to reduced survival, indicating that a negative correlation between corticosterone levels and survival may be context-dependent (see as well McEwen et al.'s review (1997) on the context-dependent effects of corticosterone on immune function).

Our study shows that corticosterone provokes behavioral modifications, probably in order to counterbalance the direct physiological costs of the metabolic stress. We further demonstrate that on the long-term corticosterone and/or its effects on behavior and/or physiology has a positive effect on male and no negative effect on female survival, which is an important determinant of fitness. Our results therefore suggest, that the production of corticosterone is, at least in common lizards, an adaptive response to environmental stressors.

\section{Acknowledgments}

The authors are grateful to Kevin Pilz, Juan Antonio Fargallo, Jean-François Le Galliard and Joël White as well as three anonymous referees for comments on this article. Caroline Naquet, Jean-François Le Galliard, and Danielle Mersch kindly assisted during the experiment. The authors acknowledge the Ecole Normale Superieure for technical support at the Biological Station of Foljuif. The work was financial supported by the Observatoire de Recherche en Environnement Nr. 53, of the Ministère de la Recherche française, MODLIFE, and the Federal Office of Education and Science BBW Nr. 01.0254 to P.S.F.

\section{References}

Astheimer, L.B., Buttemer, W.A., Wingfield, J.C., 1992. Interactions of corticosterone with feeding, activity and metabolism in passerine birds. Orn. Scand. 23, 355-365.

Avery, R.A., 1962. Notes on the biology of Lacerta vivipara L. Br. J. Herpetol. 3, 165-170.

Belliure, J., Meylan, S., Clobert, J., 2004. Prenatal and postnatal effects of corticosterone on behavior in juveniles of the common lizard, Lacerta vivipara. J. Exp. Zool. Part A 301, 401-410.

Bennett, A.F., Huey, R.B., 1990. Studying the evolution of physiological performance. Oxf. Surv. Evol. Biol. 7, 251-284.

Berger, S., Martin II, L.B., Wikelski, M., Romero, L.M., Kalko, E.K.V., Vitousek, M.N., Rödl, T., 2004. Corticosterone suppresses immune activity in territorial Galapagos marine iguanas during reproduction. Horm. Behav. 47, 419-429.

Breuner, C.W., Hahn, T.P., 2003. Integrating stress physiology, environmental change, and behavior in free-living sparrows. Horm. Behav. 43, $115-123$.

Breuner, C.W., Greenberg, A.L., Wingfield, J.C., 1998. Noninvasive corticosterone treatment rapidly increases activity in Gambel's WhiteCrowned Sparrows (Zonotrichia leucophrys gambelii). Gen. Comp. Endocrinol. 111, 386-394.

Carpenter, C.C., Ferguson, G.W., 1977. Variation and evolution of stereotyped behavior in reptiles. In: Tinkle, C.G.D.W. (Ed.), Biology of the Reptilia: Ecology and Behavior, vol. 7. Academic Press, New York, pp. 335-554.

Christian, K.A., Tracy, C.R., 1981. The effects of the thermal environment on the ability of hatchling Galapagos land iguanas to avoid predation during dispersal. Oecologia 49, 218-223.

Clobert, J., Lebreton, J.D., Allainé, D., Gaillard, J.M., 1994. The estimation of age-specific breeding probabilities from capture or resightings in vertebrate populations: II. Longitudinal models. Biometrics 50, 375-387.

Clobert, J., Oppliger, A., Sorci, G., Ernande, B., Swallow, J.G., Garland, T.J., 2000. Trade-offs in phenotypic traits: endurance at birth, growth, survival, predation and susceptibility to parasitism in a lizard, Lacerta vivipara. Funct. Ecol. 14, 675-684.

Comendant, T., Sinervo, B., Svensson, E., Wingfield, J.C., 2003. Social competition, corticosterone and survival in female lizard morphs. J. Evol. Biol. 16, 948-955.

Darlington, R.B., Smulders, T.V., 2001. Problems with residual analysis. Anim. Behav. 62, 599-602.

de Fraipont, M., Clobert, J., John-Adler, H., Meylan, S., 2000. Increased pre-natal maternal corticosterone promotes philopatry of offspring in common lizards Lacerta vivipara. J. Anim. Ecol. 69, 404-413.

DeNardo, D.F., Licht, P., 1993. Effects of corticosterone on social behavior of male lizards. Horm. Behav. 27, 184-199. 
DeNardo, D.F., Sinervo, B., 1994. Effects of corticosterone on activity and home-range size of free-ranging male lizards. Horm. Behav. 28, 53-65.

DeNardo, D.F., Sinervo, B., 1994. Effects of steroid hormone on activity and home-range size of male lizards. Horm. Behav. 28, 273-287.

Eriksen, M.S., Haug, A., Torjesen, P.A., Bakken, M., 2003. Prenatal exposure to corticosterone impairs embryonic development and increases fluctuating asymmetry in chickens (Gallus gallus domesticus). Br. Poult. Sci. 44, 690-697.

Gleeson, T.T., Dalessio, P.M., Carr, J.A., Wickler, S.J., Mazzeo, R.S., 1993. Plasma catecholamine and corticosterone and their in vitro effects on lizard skeletal muscle lactate metabolism. Am. J. Physiol. 265, R632-R639.

Greenberg, G.N., Wingfield, J.C., 1987. Stress and reproduction: reciprocal relationships. In: Norris, K., Jones, R.E. (Eds.), Hormones and Reproduction in Fishes, Amphibians, and Reptiles. Plenum, New York, pp. $461-503$.

Harvey, S., Phillips, J.G., Rees, A., Hall, T.R., 1984. Stress and adrenal function. J. Exp. Zool. 232, 633-645.

Heulin, B., 1988. Observations sur l'organisation de la reproduction et sur les comportements sexuels et agonistiques chez Lacerta vivipara. Vie Milieu 38, 177-187.

Holmes, W.N., Phillips, J.G., 1976. The adrenal cortex in birds. In: ChesterJones, I., Henderson, I. (Eds.), Endocrinology of the Adrenal CortexAcademic Press, New York, pp. 293-420.

Huey, R.B., 1974. Behavioral thermoregulation in lizards: importance of associated costs. Science 184, 1001-1003.

Huey, R.B., 1982. Phylogenetic and ontogenetic determinants of sprint performance in some diurnal Kalahari lizards. Koedoe 25, 43-48.

Huey, R.B., Bennett, A.F., John-Adler, H., 1984. Locomotor capacity and foraging behaviour of Kalahari lacertid lizards. Anim. Behav. 32, 41-50.

Jones, S.M., Wapstra, E., Swain, R., 1997. Asynchronous male and female gonadal cycles and plasma steroid concentrations in a viviparous lizard, Niveoscincus ocellatus (Scincidae), from Tasmania. Gen. Comp. Endocrinol. 108, 271-281.

Kitaysky, A.S., Kitaiskaia, E.V., Piatt, J.F., Wingfield, J.C., 2003. Benefits and costs of increased levels of corticosterone in seabird chicks. Horm. Behav. 43, 140-149.

Knapp, R., Moore, C., 1997. Male morphs in tree-lizards have different testosterone responses to elevated levels of Corticosterone. Gen. Comp. Endocrinol. 107, 273-279.

Knobil, E., Neill, J.D., 1994. The Physiology of Reproduction, vol. 2. Raven Press.

Lance, V.A., 1990. Stress in reptiles. In: Epple, A., Scanes, C.G., Stetson, M.H. (Eds.), Prospects in Comparative EndocrinologyWiley-Liss, New York, pp. 461-466.

Le Galliard, J.F., Ferrière, R., Clobert, J., 2003. Mother-offspring interactions affect natal dispersal in a lizard. Proc. R. Soc. Lond., B $270,1163-1169$.

Lecomte, J. (1993). Comportements du lézard vivipare. Ecology Thesis, Université Paris Sud.

Lecomte, J., Clobert, J., 1996. Dispersal and connectivity in populations of the common lizard Lacerta vivipara: an experimental approach. Acta Oecol. 17, 585-598.

Lin, H., Decuypere, E., Buyse, J., 2004. Oxidative stress induced by corticosterone administration in broiler chickens (Gallus gallus domesticus) 1. Chronic exposure. Comp. Biochem. Physiol., B 139, 737-744.

Littell, R.C., Miliken, G.A., Stroup, W.W., Wolfinger, R.D., 1996. SAS ${ }^{\circledR}$ System for Mixed Models. SAS Institute, Inc.
Massot, M., Clobert, J., Pilorge, T., Lecomte, J., Barbault, R., 1992. Density dependance in the common lizard: demographic consequences of a density manipulation. Ecology 73, 1742-1756.

McEwen, B.S., Biron, C.A., Brunson, K.W., Bulloch, K., Chambers, W.H., Dhabhar, F.S., Goldfarb, R.H., Kitson, R.P., Miller, A.H., Spencer, R.L., Weiss, J.M., 1997. The role of agrenocorticoids as modulators of immune function in health and disease: neural, endocrine and immune interactions. Brain Res. Rev. 23, 79-133.

Meylan, S., Clobert, J., 2005. Is corticosterone mediated phenotype development adaptive? Maternal corticosterone treatment enhances survival in male lizards. Horm. Behav., 44-52.

Meylan, S., Dufty, A.M., Clobert, J., 2003. The effect of transdermal corticosterone application on plasma corticosterone levels in pregnant Lacerta vivipara. Comp. Biochem. Physiol., A 134, 497-503.

Moore, I.T., Jessop, T.S., 2003. Stress, reproduction, and adrenocortical modulation in amphibians and reptiles. Horm. Behav. 43, 39-47.

Moore, I.T., Mason, R.T., 2001. Behavioral and hormonal responses in the male red-sided garter snake, Thamnophis sirtalis. Physiol. Behav. 72, $669-674$

Morici, L.A., Elsey, R.M., Lance, V.A., 1997. Effect of long-term corticosterone implants on growth and immune function in juvenile alligators, Alligator mississippiensis. J. Exp. Zool. 279, 156-162.

Pilorge, T., Clobert, J., Massot, M., 1987. Life history variations according to sex and age in Lacerta vivipara. Proc. 4th Ord. Gen. Meet. S.E.H., pp. $311-315$.

Pravosudov, V.V., Kitaysky, A.S., Wingfield, J.C., Clayton, N.S., 2001. Long-term unpredictable foraging conditions and physiological stress response in mountain chickadees (Poecile gambeli). Gen. Comp. Endocrinol. 123, 324-331.

Romero, L.M., Wikelski, M., 2001. Corticosterone levels predict survival probabilities of Galapagos marine iguanas during El Niño events. Proc. Natl. Acad. Sci. U. S. A. 98, 7366-7370.

Sapolsky, R.M., Romero, L.M., Munck, A.U., 2000. How do glucocorticoids influence stress responses? Integrating permissive, suppressive, stimulatory, and preparative actions. Endocr. Rev. 21, 55-89.

Silverin, B., 1998. Stress responses in birds. Poult. Avian Biol. Rev. 9, $153-168$

Sinervo, B., DeNardo, D.F., 1996. Costs of reproduction in the wild: path analysis of natural selection and experimental tests of causation. Evolution 50, 1299-1313.

Sorci, G., Clobert, J., 1999. Natural selection on hatchling body size and mass in two environments in the common lizard (Lacerta vivipara). Evol. Ecol. Res. 1, 303-316

Tataranni, P.A., Larson, D.E., Snitker, S., Young, J.B., Flatt, J.P., Ravussin, E., 1996. Effects of glucocorticoids on energy metabolism and food intake in humans. Am. J. Physiol. 271, E317-E325.

Tokarz, R.R., 1987. Effects of corticosterone treatment on male aggressive behavior in a lizard (Anolis sagrei). Horm. Behav. 21, 39-52.

Tschirren, B., Fitze, P.S., Richner, H., 2003. Sexual dimorphism in susceptibility to parasites and cell-mediated immunity in great tit nestlings. J. Anim. Ecol. 72, 839-845.

Tyrrell, C., Cree, A., 1998. Relationships between corticosterone concentration and season, time of day and confinement in a wild reptile (Tuatara, Sphenodon punctatus). Gen. Comp. Endocrinol. 110, $97-108$.

Wingfield, J.C., Ramenofsky, M., 1999. Hormones and the behavioral ecology of stress. In: Balm, P.H.M. (Ed.), Stress Physiology in AnimalsSheffield Academic Press, pp. 1-51. 